\title{
ADAPTAÇÃO AO MEIO LÍQUIDO: UMA PROPOSTA DE AVALIAÇÃO DA EDUCAÇÃO FíSICA PARA AULAS DE NATAÇÃO
}

Gabriela Rebelo da Silva ${ }^{1}$, Elinai dos Santos Freitas Schutz ${ }^{2}$ e Ruan Carlos dos Santos $^{3,4}$

${ }^{1}$ SED-SC/UDESC - Universidade do Estado de Santa Catarina, ${ }^{2}$ UNISUL Universidade do Sul de Santa Catarina, ${ }^{3} \mathrm{FAEL}$ - Faculdade Educacional da Lapa, ${ }^{4}$ UNIVALI - Universidade do Vale do Itajaí bielars4@yahoo.com.br

Acesso DOI: http://dx.doi.org/10.34059/ciejop.2019v27i1-5

\section{RESUMO}

Treinamento contempla programas com diferentes objetivos. Estudos apontam a importância da adaptação ao meio líquido nas aulas de natação. Foi utilizado um questionário validado para o proposto trabalho, composto por quatorze questões, que objetivaram investigar a importância da adaptação ao meio líquido nas aulas de natação. Esse questionário foi estruturado em duas partes: a primeira parte voltada aos dados pessoais e questões gerais relativas à atuação profissional; a segunda parte relacionada à questões específicas sobre o tema adaptação ao meio líquido. Os questionários foram aplicados com professores de natação, que trabalham em academias e escolas de natação da grande Florianópolis. Os resultados foram analisados, discutidos e apresentados em forma de gráficos e tabelas, onde concluise que a adaptação ao meio líquido, é a fase que antecede o aprendizado da natação, é através dela que o aluno terá a oportunidade de se familiarizar com o novo meio, ficar mais à vontade, experimentar novas sensações, perder seus medos e traumas, sentindo se assim mais seguro para prosseguir no processo de aprendizagem do ensino da natação.

PALAVRAS-CHAVE: Natação. Aprendizagem. Adaptação. Avaliação. Educação Física.

\section{INTRODUÇÃO}

O ensino da natação possibilita o indivíduo através da água adquirir novas vivências, novas capacidades de adaptação. Dentro do aprendizado da natação, esta se divide nas seguintes etapas: ambientação/familiarização, respiração, flutuação, deslize, mergulho/entradas na água; e, antes de tudo a adaptação ao meio líquido, que é muito importante para ajudar o indivíduo a se familiarizar e desenvolver dentro do ambiente aquático. Na fase de adaptação ao meio líquido na natação é uma das fases de aprendizagem, em que deve ser feito um processo de domínio do corpo na água, possibilitando novas experiências, sensações; de modo 
com que o indivíduo perca seus medos, receios, vergonhas e se ambientalize da melhor forma possível ao novo meio (CAMPANIÇO, 1989; SPORTMIL, 2008).

Marcon (2002) explica que, desde o princípio da vida, durante a gestação, o feto fica envolvido pelo líquido amniótico, que lhe possibilita perceber o mundo ao seu redor, proporcionando-Ihe calor e proteção, além de nutrientes necessários para o seu desenvolvimento. Esse representa, também, o primeiro contato do ser humano com a água, que, é o seu primeiro contato com a própria vida. Esse fato pode facilitar a sua futura adaptação aquática relacionada à natação, conforme estudos e propostas lúdicas que se inserem no contexto pedagógico dessas atividades como facilitador do processo de apropriação das atividades motoras aquáticas que podem ser realizados em clubes recreativos, espaços aquáticos urbanos que são destinados ao lazer (MARCON, 2002).

Através do movimento o ser humano interage com o meio ambiente e amplia seu desenvolvimento biológico, psicológico, social, cultural e evolutivo, e, para que isso ocorra, é essencial uma série variável de atividades físicas que oportunizem, motivem e orientem o ser humano a desenvolver suas capacidades de movimentos (CANÇADO, 2003). Essas atividades podem ser realizadas utilizando-se de recursos pedagógicos e formas lúdicas, buscando uma forma eficiente para a adaptação do indivíduo ao meio líquido, em que o indivíduo possa aprender a lidar com a nova experiência do meio líquido naturalmente.

Freire (2008, p.1), afirma que: inserir o lúdico na relação pedagógica no meio líquido alcança uma dimensão humana que vai além do simples entretenimento ou como recompensa por cumprimento de tarefas durante as aulas de natação, ele possibilita desvelar emoções e sensações, assim como aspectos relacionados à afetividade.

No entanto, além do lúdico é preciso conhecer bem o novo ambiente que está inserindo e adaptar-se as mudanças que este oferece. Segundo Carvalho (1987), os comportamentos são adaptados à mudança do ambiente, como no deslocamento; em terra é feito na posição vertical, com apoios fixos, as pernas servem para locomoção e os braços tem o papel de equilibrador; já na natação a posição é horizontal com apoios não fixos, as pernas fazem o papel equilibrador e os braços de locomoção. Mudanças também ocorrem com a respiração, visão, audição, temperatura corporal, entre outros, que envolvem a alteração no comportamento durante a adaptação ao meio líquido (ARAÚJO, 1997). 
Uma boa adaptação ao meio líquido resultará principalmente da relação indivíduo/água, de como este irá vivenciar esse novo desafio, de seu estado psicológico no momento de enfrentar esse novo obstáculo, porém, por vezes erroneamente esquecido ou ignorado (CAMPANIÇO, 1989). Deve seguir um processo pedagógico elaborado anteriormente de acordo com a experiência aquática de cada indivíduo, geralmente iniciado fora da água, com a adaptação do conviver, apresentação dos materiais que serão utilizados, e uma breve conversa para que se saiba os objetivos do aprendiz com o ensino da natação, para deixá-lo mais à vontade e que também devem ser feitos de forma gradativa, ou seja, do mais fácil para o mais difícil (SPORTMIL, 2008).

Antes de o indivíduo começar a aprender os quatro nados é preciso que ele esteja bem adaptado com o meio líquido, reconhecendo seus possíveis movimentos dentro deste ambiente, fazendo isto de forma prazerosa e motivadora (CARVALHO, 1987). A partir do momento que o indivíduo assimila todos esses passos, estando seguro de si e sem receios, ele está apto para iniciar a nadar e se aprimorar na natação. Assim, é através da adaptação ao meio líquido o aluno adquire segurança e experiência para dar continuidade à próxima etapa: o ensino dos nados na natação.

A partir destas considerações, indagou-se: Qual a importância atribuída por professores à fase de adaptação ao meio líquido nas aulas de natação? A adaptação ao meio líquido é "o processo que envolve a iniciação à natação, recorrendo ao domínio do corpo na água" (CAMPANIÇO, 1989, p.4). É uma fase de descoberta, ou seja, uma aproximação ao novo meio. É nesse período que o aprendiz explora o meio líquido buscando segurança, autonomia e também uma relação afetiva com o ambiente em que está se inserindo (CORAZZA et al., 2005).

De uma boa adaptação ao meio líquido que podemos perceber no indivíduo a capacidade de adquirir: Maior autonomia na água; maior facilidade nos deslocamentos; menor resistência ao entrar na água (menor medo); familiarização com os materiais e com os métodos utilizados durante as atividades; maior interação entre alunos - professores (MEZZAROBA, 2008, p.1). Quando a adaptação é realizada de forma bem sucedida, atuando com a atenção, descontração, segurança e experiência do professor, faz com que o aluno adquira confiança, quebrando assim as barreiras do medo e da insegurança; então ele começa a se soltar e desfrutar do prazer que a água proporciona (SPORTMIL, 2008).

Fórum Internacional de Qualidade de Vida e Saúde - Curitiba, 15 de junho de 2019 
Kerbej (2002), aponta que já nesta fase pode-se observar alguns benefícios como o de fortalecer a musculatura, melhorar a capacidade cardíaca, ativar e melhorar da mobilidade articular; e um sono mais tranquilo, reforçar o apetite, desenvolver a estabilidade emocional e a autoconfiança, proporcionar sociabilização.

Velasco (1995), afirma que a atividade na água traz segurança, recreação, mais independência, mais espontaneidade, melhoria do reflexo (resposta a estímulos), profilaxia contra resfriados, mais confiança nos relacionamentos, desenvolvimento físico e psíquico, objetivando formar cidadãos saudáveis e hábeis mentalmente. Os requisitos básicos que o indivíduo deve ter ao iniciar a natação é o conhecimento do ambiente que irá frequentar e os critérios estabelecidos pelo mesmo; facilitando assim a sua adaptação ao meio líquido e perda de inibição e receio. O segundo passo é a segurança e confiança que o professor deve proporcionar ao iniciante, para que ele possa se sentir mais seguro e assim prosseguir no processo de ensino dos nados, que começa sempre pelo trabalho de respiração adequada à natação, a seguir flutuar, deslizar e por último, mergulhar (CARVALHO, 1987). Nota-se a necessidade de uma adaptação ao meio líquido na natação, de uma forma lenta e gradual, de forma que o indivíduo se acostume com este novo meio, e assim tome gosto e em consequência, receberá a sequência do ensino da natação (CARVALHO, 1987).

\section{METODOLOGIA}

A pesquisa caracteriza-se como sendo do tipo descritiva, diagnóstica de campo (CERVO \& BERVIAN, 1983). Participaram deste estudo 15 professores de natação, 12 do sexo feminino e três do sexo masculino, que trabalham em academias ou escolas de natação da Grande Florianópolis. Os entrevistados apresentaram uma média de idades entre 35,8 anos. A maioria são pós graduados e quatro somente graduados. Todos responderam que possuem experiência na área de atividades aquáticas; somando se todos os anos de atuação dos entrevistados, tem-se uma média de 13,4 anos atuação na área. E todos os entrevistados responderam que sentem se motivados com o trabalham que realizam.

Foi desenvolvido um questionário para o proposto trabalho apresentado no apêndice um (1). O questionário foi composto por quatorze questões, 12 do tipo aberta, uma (1) fechada e uma (1) mista que objetivaram investigar a importância da Fórum Internacional de Qualidade de Vida e Saúde - Curitiba, 15 de junho de 2019 
adaptação ao meio líquido nas aulas de natação. Esse questionário foi estruturado em duas partes: a primeira parte voltada aos dados pessoais e características gerais relativas à atuação profissional; a segunda parte relacionada ao tema adaptação ao meio líquido.

O questionário foi validado no quesito clareza por estudantes de educação física do Centro de Ciências da Saúde e do Esporte, da Universidade do Estado de Santa Catarina. Para cada questão os alunos deveriam responder: confuso, pouco claro e claro. As questões respondidas como confusas foram eliminadas do questionário, as respondidas como pouco claras foram reformuladas e as questões respondidas como claras foram mantidas. Para validação de conteúdo os questionários foram avaliados por profissionais da área de educação física, que trabalham com natação. Nas respostas estes profissionais deveriam classificá-las como: inválida, pouco válida e muito válida. As questões respondidas como inválidas foram eliminadas do questionário, as respondidas como pouco válidas foram reformuladas e as questões respondidas como válidas foram mantidas.

Esta pesquisa levou em conta os princípios éticos de respeito à autonomia das pessoas, de acordo com a Resolução n. 196, de 10 de outubro de 1996 do Conselho Nacional de Saúde. Precedendo a coleta de dados, foi solicitada a autorização dos responsáveis pelas academias e escolas de natação nos municípios de São José e da Grande Florianópolis e a aprovação do protocolo de intervenção do estudo pelo Comitê de Ética em Pesquisa com Seres Humanos da Universidade do Estado de Santa Catarina (UDESC).

A coleta de dados ocorreu em horário previamente marcado com o professor, no seu local de trabalho. Os professores foram orientados a preencherem o questionário e a qualquer dúvida solicitar informações do pesquisador. Os dados foram tabulados e armazenados em um banco de dados. Para analisar, apresentar e descrever os dados foi utilizada a estatística descritiva. Os dados foram transportados para o programa excel, no qual foram agrupadas as respostas semelhantes, com intuito de chegar a uma resposta com fatos comum entre todas e assim realizadas a estatística descritiva. 


\section{RESULTADOS E DISCUSSÕES}

Este estudo buscou analisar questões relacionadas à adaptação ao meio líquido nas aulas de natação. Neste capítulo estão apresentados os resultados e discussões da pesquisa sobre a importância atribuída por professores à fase de adaptação ao meio líquido nas aulas de natação, realizada nas academias da Grande Florianópolis. A pesquisa foi realizada com 15 professores de natação das academias da Grande Florianópolis, sendo a maioria dos entrevistados do sexo feminino, com um total de 12 e três do sexo masculino; apresentando idades entre 25 a 30 anos (quatro deles), sete entre 31 a 40 anos e quatro entre 41 a 50 anos. A maioria dos entrevistados, são pós graduados e quatro somente graduados. Todos responderam que possuem tempo de serviço na área de atividades aquáticas, somando se todos os anos de atuação dos entrevistados, tem-se uma média de 13,4 anos atuação na área.

Sobre a motivação quanto o trabalho que realizam, observou-se que todas as respostas sobre motivação foram positivas, eles sentem-se motivados com o trabalho que realizam. Nos dados obtidos sobre se o local de trabalho oferece subsídios suficientes para desenvolver adequadamente a atividade profissional, 11 dos entrevistados responderam que "Sim. Porque o ambiente é agradável (boa estrutura física); tem organização, regras bem estabelecidas, diálogo (com equipes de professores) e variedade de materiais. Além do apoio técnico e humano". Outro professor respondeu que sim, pois os objetivos determinados aos alunos são atingidos. Outro respondeu que sim, oferece uma boa estrutura física, mas torna-se necessário a aquisição de vários materiais. Outro ainda que sim, temos materiais necessário para as aulas. Além do incentivo de um curso de atualização por ano. $\mathrm{E}$ um outro respondeu que em partes. A estrutura poderia sofrer manutenção.

É de suma importância ter um bom ambiente de trabalho com uma boa estrutura, bons materiais, incentivos, que seja organizado, enfim; tudo isso para que o profissional se sinta seguro e estimulado para realizar o seu trabalho, facilitando também o aprendizado do aluno. 
Tabela 1 - O ensino da natação para um aluno iniciante - etapas

\begin{tabular}{|c|c|}
\hline Desenvolvimento do ensino da natação & Total \\
\hline Com a adaptação ao meio líquido. & 11 \\
\hline Adaptação do rosto, controle do corpo na água... & 3 \\
\hline Se for criança:... & 1 \\
\hline
\end{tabular}

Fonte: Dados obtidos na pesquisa.

Em relação ao desenvolvimento do ensino da natação para iniciantes, pode se perceber que a maioria das respostas, foram que desenvolvem através da adaptação ao meio líquido. Respiração, flutuação, propulsão (deslize/deslocamentos), saltos e mergulhos. Início do trabalho perna; início do trabalho braço; coordenação nado com respiração. Três responderam que através da adaptação do rosto na água, fazer com que o aluno aprenda a controlar seu corpo dentro da água, elevadores, propulsão de pernas com apoio de material utilizando-se dos elevadores e depois início as braçadas. Depois de adaptado o rosto na água inicia o processo de respiração, flutuação com e sem material, etc. E um respondeu que se for criança: adaptação ao ambiente (espaço físico); adaptação ao professor (confiança), adaptação ao meio líquido, junto com alguns deslocamentos.

Alguns autores ressaltam as etapas para o processo de adaptação ao meio líquido, como por exemplo Machado (1978), que diz que se deve seguir o ensinamento com a familiarização, respiração, flutuação, noção de propulsão, mergulho elementar. De acordo com Araújo (1997), para atingir os objetivos da natação o método pode ser dividido em cinco etapas: ambientação / familiarização, respiração (Imersão), flutuação, deslizes e mergulho / entrada na água. Observa se que as respostas da pesquisa seguem praticamente a sequência utilizada por Araújo, tendo alguns termos parecidos e alguns itens acrescentados no processo de aprendizagem da adaptação ao meio líquido.

Nos resultados obtidos sobre se o profissional trabalha a adaptação ao meio líquido nas suas aulas de natação, 15 dos entrevistados responderam de forma positiva (sim, claro, com certeza) que trabalham a adaptação ao meio líquido nas suas aulas de natação. Entre as respostas 12 delas foram que sim, claro, com certeza. Um, foi sim, isto é de fundamental importância para o aprendizado do nado. Um, que sim, em etapas: inicial, média e desenvolvida. E outra ainda que sim, 
mesmo após o aprendizado sempre faço alguns desafios novos, como tocar alguma parte do corpo no fundo da piscina, boiar de diversas maneiras, fazer cambalhotas, etc.

Ao entrar em contato com o meio líquido, o indivíduo começa a experimentar situações que são diferentes do que está acostumado, implicando em mudanças em seu comportamento natural como: respiração, visão, deslocamento, entre outros; por esse motivo deve se sempre iniciar a aprendizagem da natação pela adaptação ao meio líquido, pois é uma forma do aluno se adaptar ao novo meio, se tornando mais seguro de si e seus movimentos, para assim começar o aprendizado da natação propriamente dito.

Tabela 2 - Importância do trabalho de adaptação ao meio líquido nas aulas de natação

\begin{tabular}{|c|c|}
\hline Importância de trabalhar a adaptação ao meio líquido & Total \\
\hline$\dot{E}$ a parte mais importante & 14 \\
\hline Ambientalização, socialização & 1 \\
\hline
\end{tabular}

Fonte: Dados obtidos na pesquisa.

As respostas apresentadas na tabela acima revelam que os entrevistados, na sua maioria, responderam que a adaptação ao meio líquido é a parte mais importante. A adaptação é a base para o aprendizado, uma boa adaptação promove um aprendizado mais rápido dos nados mais tarde (o corpo fica mais solto, mais relaxado para nadar; e, já tem mais consciência da técnica pode perceber/controlar melhor seu corpo, seus movimentos na água). Desenvolve a autoconfiança, faz perder o medo. Um respondeu que é importante por causa da ambientalização: espaço físico e água; socialização.

Para Barros (2003), a adaptação ao meio líquido é fase inicial do processo de ensino da aprendizagem da natação que visa à ambientação do aluno ao meio líquido levando-o a ter uma intimidade com a água, sentindo-se seguro, e obtendo o domínio das habilidades básicas da natação. 
Figura 3 - Diferença no desenvolvimento de atividades para a fase de adaptação ao meio liquido para crianças e adultos.

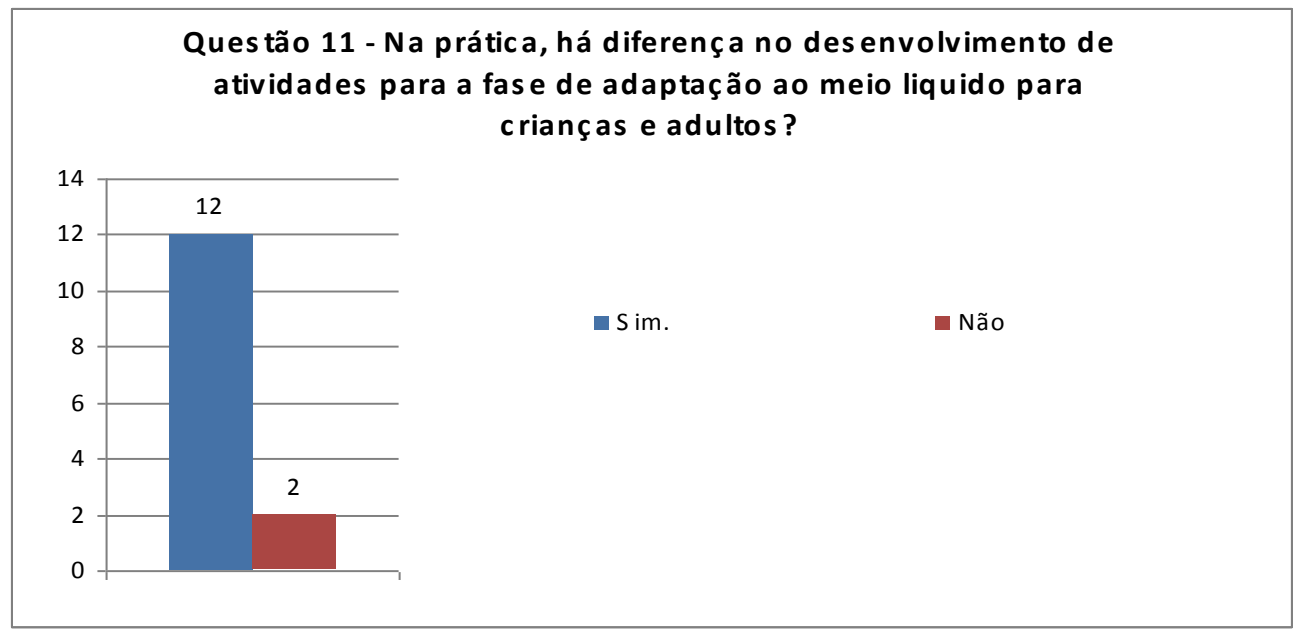

Fonte: Dados obtidos na pesquisa.

Foi perguntado aos profissionais se há diferença no desenvolvimento de atividades para a fase de adaptação ao meio liquido para crianças e adultos; 8 dos entrevistados responderam que sim, há diferença. A diferença está em como vai ser passada as informações: para a criança de maneira mais lúdica (figurada, recreativa, brincadeiras), enquanto que para adultos a linguagem deve ser mais informativa, especificando os objetivos e as particularidades dos exercícios (mais técnico, realizar desafios físicos e psicológicos). Um respondeu que com certeza. Temos que nos adequar ao público ao qual estamos trabalhando; informarmos das vivências que trazem e o que esperam de nós. Dividir apenas em crianças e adultos é simples demais. Dar aula de natação não deve se resumir em: fazer elevador, pranchinhas para lá e para cá. Um respondeu que sim, os adultos tem muito mais medo ou trauma na água, o tempo de adaptação é um pouco mais demorado. Na fase de flutuação e soltura dos materiais demora mais tempo. Três responderam que sim. As crianças geralmente têm menos medo e não tem vícios; aprende tudo brincando, se divertindo. E o adulto, tem seus traumas, mas com dedicação e paciência aprende igual. E dois responderam que não. Vai haver diferença é se o aluno tem medo ou não.

Navarro (1995), diz que o aprendizado do indivíduo deve ser estimulado a realização e a possibilidade de se familiarizar, para que adquira confiança na água. O primeiro objetivo a se conseguir, é eliminar a rigidez muscular, produzida pelo medo da água. E o segundo, ensinar a correta mecânica respiratória. É preciso ter 
paciência para que o indivíduo comece a se sentir à vontade na água e a partir disso desenvolver um trabalho que o leve, enfim, a nadar (locomover-se na água).

Tabela 4 - Materiais utilizados na fase de adaptação ao meio líquido.

\begin{tabular}{|c|c|}
\hline Materiais que geralmente utiliza na fase de adaptação & Total \\
\hline Brinquedos que flutuam, que submergem & 8 \\
\hline Espaguete, prancha, pull boal... & 3 \\
\hline Com os adultos pranchas e aquatubos, com as crianças brinquedos & 1 \\
\hline Escada, barra de ferro, raia... & 1 \\
\hline Exercícios sem material & 2 \\
\hline
\end{tabular}

Fonte: Dados obtidos na pesquisa.

Observando as respostas acima, verifica se que a maioria dos entrevistados responderam que utilizam brinquedos que flutuam, que submergem, espaguetes, tapetes, arcos, bolas, pranchas, etc. Estimulam deslocamentos variados e com mudança de direção, a imersão (mergulho) ou flutuação. De forma com que o aluno se adapte. Outros responderam que através de aquatubos (espaguete): flutuação; prancha: deslocamentos; Pull boll: idem prancha; canudos: expiração; bolas de isopor: expiração; bichinhos plásticos: pegar; argolas: mergulhar, noção espacial dentro da água, propulsão de pernas; aros: mergulhar, propulsão de pernas; bóiasbraço: deslocamento, flutuação. Um respondeu que primeiramente objetos fixos tipo escada, barra de ferro, raia, depois aquatubos, prancha, tudo com o objetivo de passar segurança para o aluno. Um respondeu que com os adultos pranchas e aquatubos com o objetivo de estabilizar a flutuação. Com as crianças pranchas, aquatubos, brinquedos flutuantes e brinquedos que afundam, com objetivos de estabilizar a flutuação e incentivar a imersão. Dois dos entrevistados responderam que na fase de adaptação procuram realizar exercícios sem material, apenas com auxílio do professor (que estará na água).

As atividades podem ser realizadas utilizando-se recursos pedagógicos, buscando uma forma eficiente para a adaptação do indivíduo ao meio líquido, em que o indivíduo possa aprender a lidar com a nova experiência do ambiente líquido naturalmente. Segundo Cançado (2003), para que isso ocorra, é essencial uma série variável de atividades físicas que oportunizem, motivem e orientem o ser humano a desenvolver suas capacidades de movimentos. Freire (2008) diz que "inserir o lúdico na relação pedagógica no meio líquido alcança uma dimensão humana que vai além do simples entretenimento ou como recompensa por cumprimento de tarefas 
durante as aulas de natação, ele possibilita desvelar emoções e sensações, assim como aspectos relacionados à afetividade".

Tabela 5 - Tempo médio para o desenvolvimento da etapa de adaptação ao meio liquido

\begin{tabular}{|c|c|}
\hline Tempo médio para o desenvolvimento da adaptação & Total \\
\hline Sim & 3 \\
\hline Não & 12 \\
\hline
\end{tabular}

Fonte: Dados obtidos na pesquisa.

Diante da pergunta se existe um tempo médio para o desenvolvimento da adaptação ao meio líquido, evidencia-se que a maioria dos entrevistados responderam que não existe um tempo médio para o desenvolvimento da etapa de adaptação ao meio líquido. Pois existem pessoas que possuem mais habilidade e facilidade, enquanto outras tem mais dificuldades, não por conta da capacidade física, mas por fatores psicológicos. Cabe o professor ter paciência e sensibilidade para desenvolver os exercícios que se adequem a cada indivíduo (estímulos adequados). Não tem como prever o tempo (cada aluno tem o seu tempo de adaptação). Um respondeu que sim, para criança até duas semanas, para adultos dependendo do medo até um mês. Um respondeu que sim. Porque cada um tem necessidades e objetivos diferentes. Um respondeu que sim, aproximadamente oito aulas.

De acordo com Gomes (1995), é importante salientar, que a adaptação ao meio líquido é a base para outras etapas de ensino da natação, e se esta não for respeitada e bem trabalhada, poderá acarretar em traumas ao indivíduo e, talvez a aversão pela natação. Sportmil (2008) cita que o fator tempo é muito importante e deve ser respeitado por professores, pais, amigos e pela própria pessoa.

Tabela 6 - Principal motivo que leva o aluno iniciante a desistir das aulas de natação

\begin{tabular}{|c|c|}
\hline Motivo que leva o iniciante a desistir da natação & Total \\
\hline Dificuldade de coordenação para nadar, pressa em aprender & 6 \\
\hline Aulas chatas & 1 \\
\hline Falta de motivação, interesse. & 1 \\
\hline Cobrança de mais & 2 \\
\hline Medo de não conseguir superar seus medos & 3 \\
\hline Falta de paciência e atenção & 1 \\
\hline
\end{tabular}

Fonte: Dados obtidos na pesquisa. 
Analisando o motivo que leva o aluno iniciante a desistir das aulas de natação, pode se observar nas respostas, que seis dentre os 15 entrevistados responderam da seguinte forma, "o principal motivo que leva o aluno a desistir das aulas de natação é a dificuldade de coordenação para nadar (braçada, pernada, respiração, flutuação). Pressa em aprender. Como não conseguem (acreditam que vai demorar muito para aprender), se frustram e acabam desistindo. Medo, vergonha, insegurança". Um respondeu que "em alguns locais as aulas de natação são extremamentes chatas. Os alunos são tratados de forma impessoal. Acredito que os profissionais precisam com urgência sanar esta falha na sua formação". Um respondeu que é pela "falta de motivação (por falta de estímulos dos pais e/ou dos profissionais), falta de interesse do aluno. Eventos negativos (caldos, afogamentos), aulas desestimulantes ou inapropriados (para idade ou indivíduo)". Um respondeu que os motivos "são vários: cobrança de mais (tanto dos pais, professor, quanto de si mesmo), instalações inadequadas, água fria, falta de empatia com o método ou com o professor, etc". Dois responderam que por "medo de não conseguir superar seus medos; não gostar do meio líquido; a falta de paciência tanto do aluno quanto do professor; a falta de confiança no professor e/ou em si mesmo; a falta de disciplina e superação". Três responderam que é "quando o aluno não é estimulado e motivado pelo professor. Quando o professor perde a paciência e não dá a devida atenção. Saber da real dificuldade de cada um para melhor desenvolver a aprendizado. Água fria/inverno". Um respondeu que "muitos não são persistentes e disciplinados o suficiente para aguentar todas as etapas do desenvolvimento da adaptação, pois requer muita paciência não só do professor como do aluno. Em segundo lugar, penso que seja a insegurança do aluno".

Para Lima (1999, p.38) cita que a "aprendizagem é um processo de ação recíproca entre o ser humano e o meio biológico ou cultural". Desta forma deve se dar tempo ao tempo e sempre incentivar e ajudar os iniciantes a superarem seus medos, receios, ansiedades, falta de motivação, enfim.

\section{CONCLUSÃO}

A adaptação ao meio líquido é a fase que antecede o aprendizado da natação, é através dela que o aluno terá a oportunidade de se familiarizar com o novo meio, ficar mais à vontade, experimentar novas sensações, perder seus medos 
e traumas, sentindo se assim mais seguro para prosseguir no processo de aprendizagem do ensino da natação.

Dentre os fatores analisados, observou se que os entrevistados se mostram motivados e que no seu local de trabalho oferecem subsídios necessários para que os mesmos realizem um bom trabalho, pois apresentam uma boa estrutura física, organização, regras, materiais diversificados e incentivos. Inicialmente, trabalham a adaptação ao meio líquido antes da aprendizagem da natação propriamente dita, realizando um trabalho para que o indivíduo se sinta mais seguro. Desta forma, na fase de adaptação ao meio líquido, seguem as etapas como: respiração, flutuação, propulsão (deslize/deslocamentos), saltos e mergulhos, preconizados na literatura. Também realizam o início do trabalho perna; início do trabalho braço; coordenação do nado com respiração.

Contudo, se verifica que há diferenças no processo de ensino da adaptação ao meio líquido. Que a diferença está em como vai se passar às informações, de modo que para as crianças pode ser realizado de uma maneira mais lúdica (recreativa), e para adultos pode se utilizar uma linguagem mais informativa, especificando os objetivos e as particularidades dos exercícios. Nesta etapa de adaptação, podemos verificar que podem ser utilizados vários materiais para ajudar no processo de adaptação ao meio líquido, assim como brinquedos que flutuam, que submergem, espaguetes, tapetes, arcos, bolas, pranchas, etc. Que estimulam deslocamentos variados e com mudança de direção, também a imersão (mergulho) ou flutuação. De forma com que o aluno se adapte.

E ainda, que não se deve exigir um tempo médio para o desenvolvimento da etapa de adaptação ao meio líquido. Pois cada pessoa tem seu próprio tempo, algumas possuem mais habilidades e facilidades que outras. Evitando assim, que o aluno desista de aprender; ora por dificuldades de coordenação, por medo, vergonha, insegurança, pressa, enfim, não devem colocar isso como barreira e se frustrarem.

Adaptação ao meio líquido, sendo esta a base para o aprendizado pode promover um aprendizado mais rápido das próximas etapas do ensinamento da natação, o indivíduo já tem mais consciência da técnica e pode perceber/controlar melhor seu corpo, seus movimentos na água. Diante dos dados observados, é possível relatar sobre a importância da adaptação ao meio líquido, onde tanto as literaturas quanto os profissionais entrevistados trazem que é a fase inicial, a mais Fórum Internacional de Qualidade de Vida e Saúde - Curitiba, 15 de junho de 2019 
importante; que a partir de uma boa adaptação se promove o ensino dos nados de maneira facilitada, com mais técnica, consciência e controle dos movimentos corporais. A quantidade de entrevistados nesse trabalho foi pequena, mais verifica se uma proximidade no que diz respeito às respostas dos entrevistados na realidade atual, e, quanto se comparado às literaturas.

\section{REFERÊNCIAS}

BARBOSA, J. J. Você pode levar seus bebês à natação. Revista Esportes Aquáticos: NADAR. São Paulo, v. IX, n. 83, 1995. Mensal.

BARROS, R. C. de. O papel do Brincar na etapa de adaptação ao meio líquido para adulto. 2003.

CAMPANIÇO, J. A Escola de Natação: 1 ${ }^{\text {a }}$ fase aprendizagem. Lisboa: Ministério da Educação - Desporto e Sociedade. 1989.

CANÇADO, L. M. Influência da natação no desenvolvimento motor de crianças na fase pré-escolar. 2003. 46 f. Trabalho de conclusão de curso (Especialização) Universidade do Estado de Santa Catarina, Florianópolis, 2003.

CARVALHO, C. de. Introdução a Didática da Natação. Adaptação ao Meio Líquido. Lisboa: Compedium, 1987.

CORAZZA, S. T.; PEREIRA, É. F.; VILLIS, J. M. C. Propriocepção e a familiarização ao meio líquido. Revista Digital - Buenos Aíres - Año 10 - o 82 - Marzo de 2005.

FREIRE, M.; SCHWARTZ, G. M. Afetividade nas aulas de natação: mediação do professor. Revista Digital - Buenos Aíres - Año 10 - no 94 - Marzo de 2008.

GOMES, W. D. F. Natação: Uma alternativa Metodológica. Rio de Janeiro: Sprint, 1995.

KERBEJ, F. C. Natação. Algo mais que 4 nados. São Paulo: Manole, 2002.

LIMA, W. U. de. Ensinando Natação. São Paulo: Phorte, 1999.

MACHADO, D. C. Metodologia da Natação. São Paulo: E.P.U., 1978.

MEZZAROBA, C.; MOREIRA, E. L.; RODRIGUES, L. A. D.; SILVEIRA, M. da R.; ARINS, F. B.; BOOS, P. Vivenciando o corpo no ambiente líquido: um relato de experiência. Revista Digital - Año 10 - 94 - Marzo de 2006.

NAVARRO, F. Hawa El Domínio Pela Natacion. Madrid: Gimnos, 1995.

SANTOS, C. A. dos. Natação: ensino e aprendizagem. Rio de Janeiro: Sprint, 1996. 
SPORTMIL. Conheça melhor a natação.2008. Disponível em: <http://www.sportmil.com.br>. Acesso em: 30 de abr. 2018.

VELASCO, C. G. Antes de andar, eles já nadam! Revista Esportes Aquáticos. NADAR. Release Editorial - Mensal - Ano X n.86. Mai, 1995. 